\title{
A trajetória histórica da constituição do marco legal das ações afirmativas
}

\author{
The historical trajectory from legal framework of affirmative actions constitution \\ Cassia Engres MOCELIN* \\ Celso José MARTINAZZO** \\ Gleny Terezinha Duro GUIMARÃES ${ }^{* * *}$
}

\begin{abstract}
Resumo: Este artigo, construído a partir de revisão bibliográfica e documental, versa sobre o processo sóciohistórico de constituição do marco legal das ações afirmativas no Brasil, por meio da sistematização das proposituras no âmbito do Legislativo e do Executivo. Somado a isso, destaca o protagonismo do movimento negro brasileiro em pautar o debate acerca da questão racial e compelir o Estado a assumir uma postura mais ativa como resposta ao processo de exclusão e discriminação social vivenciado pela população negra no país. Evidencia a compreensão da questão racial como uma das expressões da questão social que se apresenta cotidianamente à intervenção profissional do/a assistente social. Razão pela qual deve ser tema de problematização e produção de conhecimento, tendo vista a necessidade de criação de ações e mediações profissionais que estejam direcionadas a essa demanda contemporânea.
\end{abstract}

Palavras-chave: Ações afirmativas. Cotas. Marco legal. Questão racial.

\begin{abstract}
This article, which was based on a bibliographical and documentary review, deals with the sociohistorical process of the formation of the legal framework of Affirmative Actions in Brazil, through the systematization of proposals within the scope of Legislative and the Executive process. In addition, it emphasizes the role of the Brazilian black movement to raising the debate about the race issue and in compelling the State to take a more active stance in response to the process of exclusion and social discrimination experienced by the black population in the country. It evidences the understanding of the race question as one of ways in which this social issue presents itself daily in professional intervention by social workers. This is the reason why it should be a topic of problematization and knowledge production, considering the need to create professional actions and mediations which are directed to this contemporary demand.
\end{abstract}

Keywords: Affirmative actions. Quotas. Legal framework. Race issue.

Submetido em: 17/7/2017. Aceito em: 26/3/2017.

\footnotetext{
* Assistente Social. Mestra em Extensão Rural (UFSM). Doutoranda no Programa de Pós-Graduação em Serviço Social da PUCRS. Assistente Social da Universidade Federal de Santa Maria (UFSM) na Pró-Reitoria de Assuntos Estudantis (UFSM/PRAE, Santa Maria (RS), Brasil). Avenida Roraima, $\mathrm{n}^{0}$ 1000, Bairro Camobi, CEP: 97105-9000, Santa Maria (RS). E-mail: <cassiaengres@hotmail.com>. ORC ID: $<$ https://orcid.org/o0oo-0002-3751-5580>.

** Pedagogo. Pós-doutor pela Universidade do Minho (Uminho). Professor titular do Departamento de Humanidades e Educação e do Programa de Mestrado e Doutorado em Educação nas Ciências da Universidade Regional do Noroeste do Estado do Rio Grande do Sul (UNIJUí, Ijuí (RS), Brasil). Rua do Comércio, 30oo, Bairro Universitário, CEP: 98700-ooo, Ijuí (RS). E-mail: <martinazzo@unijui.edu.br>. ORC ID: <https://orcid.org/o0oo-0001-6376-3409>.

*** Assistente Social e Pedagoga. Pós-Doutorado em Serviço Social pela Universidade Católica Portuguesa Lisboa (2005). Professora na Escola de Humanidades e no Programa de Pós-Graduação em Serviço Social da Pontifícia Universidade Católica do Rio Grande do Sul (PUCRS, Porto Alegre (RS), Brasil). Avenida Ipiranga, 6681, Bairro Partenon, CEP: 90619-900, Porto Alegre (RS). E-mail: <gleny@pucrs.br>. ORC ID: $<$ https://orcid.org/oooo-0001-7465-1330>.
} 


\section{INTRODUÇÃO}

Brasil é notadamente conhecido como um dos países mais desiguais, fruto da sua

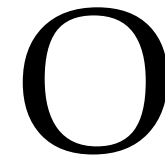
formação social, econômica e política que priorizou o trabalho escravo, a grande propriedade de terra e a monocultura, deixando grande parte da população excluída da riqueza socialmente produzida. Tais desigualdades se expressam em nossos indicadores econômicos e sociais através da elevada concentração de renda e de terra, dos altos índices de violência de gênero, geração e etnia, do analfabetismo, da pobreza estrutural, da exclusão e discriminação social.

No intuito de responder às demandas da população e no sentido de minimizar os efeitos dessa desigualdade social e estrutural, o Estado brasileiro sempre lançou mão das políticas públicas e sociais, as quais mantiveram, desde sua gênese e durante todo seu desenvolvimento, um caráter fragmentado, assistemático e seletivo. Além disso, reforçaram o critério do mérito, da benesse, da função de controle social aos trabalhadores, necessário ao desenvolvimento e aprofundamento das relações sociais capitalistas, em vez de se constituírem alicerçadas em uma cultura de direitos pela ótica universalizante, da cidadania e da emancipação dos sujeitos. Nesse sentido, Behring (2009) diz que as políticas sociais

\footnotetext{
[...] são concessões/conquistas mais ou menos elásticas, a depender da correlação de forças na luta política entre os interesses das classes sociais e seus elementos envolvidos na questão. No período de expansão, a margem de negociação se amplia; na recessão, ela se restringe (BEHRING, 2009, p. 315-316).
}

Importa destacar que esse movimento elástico das políticas sociais ficou evidenciado na década de 1980, que se tornou pródiga em participação popular, tendo em vista o início da erosão da ditadura militar no Brasil, somada à Lei da Anistia e aos diversos movimentos sociais. Assim, criaram-se as condições sociais e políticas necessárias para que velhas e novas demandas ganhassem notoriedade e visibilidade social adentrando a agenda do Estado. Destacam-se o debate sobre a desigualdade racial e as ações afirmativas agendadas através do Movimento Negro.

Desde a década de 1980 até o atual entendimento acerca das ações afirmativas, diversas propostas foram construídas a partir dos movimentos sociais, do Legislativo, do Executivo e tendo o Judiciário um papel esclarecedor nessa questão. Ao explicar o processo de juridificação dos direitos, Couto (20103) afirma que "[...] a positivação, ou seja, a transformação de uma norma em lei é uma das características da sociedade moderna [...]” (COUTO, 2010, p. 53), no sentido de efetivar os acordos estabelecidos na órbita das relações sociais.

Por causa do entendimento de que a questão racial se apresenta como uma das manifestações da questão social e que possui rebatimentos no cotidiano profissional do/a assistente social, essa temática exige, além da compreensão do processo de produção e reprodução das relações sociais em uma sociedade capitalista, a criação de ações e mediações profissionais que estejam direcionadas a esta demanda contemporânea.

Diante desses pressupostos, elaborou-se o presente artigo a partir das primeiras aproximações e construções teóricas que serão apresentadas, posteriormente, em tese de doutorado.

Argum., Vitória, v. 10, n. 1, p. 293-308, jan./abr. 2018. 
Esta reflexão objetiva apresentar uma revisão bibliográfica e documental sobre o processo sócio-histórico de constituição das ações afirmativas cotejando o seu arcabouço legal.

Para dar conta dessa abordagem, o texto está organizado em três partes. Na primeira, discutem-se as ações afirmativas e a sua instauração em âmbito internacional. A segunda parte centra-se nas ações afirmativas e o seu desenvolvimento no Brasil. Por fim, apresenta-se a trajetória da constituição do marco legal dessas ações por meio da sistematização das proposituras no âmbito do Legislativo e do Executivo.

\section{AÇÕES AFIRMATIVAS EM OUTROS PAÍSES}

As ações afirmativas vêm sendo implantadas em diversos países no sentido de responder às demandas de movimentos sociais e elevar as condições de vida de grupos historicamente excluídos, marginalizados e discriminados. Essas ações tiveram seu início na Índia com a Constituição Indiana de 1949. Desde então, existe a previsão constitucional e a obrigatoriedade da política de cotas para a contratação no serviço público em todos os órgãos estatais e na educação de ensino superior, em benefício das classes desfavorecidas, naquele caso, os dalits (SILVA, 2010; FERES JUNIOR; DAFLON, 2015).

Entretanto, foi nos Estados Unidos, na década de 1960, que o debate acerca das ações afirmativas ganhou notoriedade e projetou lideranças como Martin Luther King Jr., Malcom X e organizações negras marxistas, como os Panteras Negras. Conforme Moehlecke (2002), nos EUA havia reivindicações democráticas, expressas principalmente no movimento pelos direitos civis, cuja bandeira central foi a extensão da igualdade de oportunidades a todos, ou seja, entre brancos e negros. Também começaram a ser eliminadas as leis segregacionistas vigentes no país, e o movimento social negro surge como o seu principal protagonista.

No rastro desse contexto, desenvolve-se a ideia de uma ação afirmativa que exige do Estado, além da garantia de leis antissegregacionistas, uma postura ativa, logo afirmativa, no intuito de melhorar as condições de vida e trabalho da população negra. Então, em o6 de março de 1963, o presidente John F. Kennedy assina a Ordem Executiva n. 10.925 e denomina de ações afirmativas as medidas para promover a igualdade entre negros e brancos.

Tais ações não se restringiram à Índia e aos Estados Unidos. Outras nações também passaram a ser signatárias de ações afirmativas. O Canadá adotou políticas afirmativas a partir da década de 1960, por influência dos EUA e da Declaração Universal dos Direitos Humanos e por meio do Ato Constitucional de 1982, que introduziu cotas no parlamento para os esquimós. A Malásia adotou um sistema de cotas em 1968 para que os malaios pudessem ter direitos iguais aos chineses, já que praticamente não tinham acesso ao ensino superior e ao serviço público. No Sri Lanka, as cotas objetivavam favorecer os cingaleses prejudicados em relação aos tâmeis. Países europeus adotaram ações afirmativas na década de 1980 e a África do Sul na década de 1990 (SILVA, 2007; SILVA, 2010).

No Brasil, o Programa Nacional de Ações Afirmativas foi instituído com o Decreto no 4.228, de 13 de maio de 2002 (BRASIL, 2002C) que integra ações nas áreas de educação, saúde, trabalho, juventude, mulheres, entre outras. Resultou do comprometimento do Estado brasileiro assumido na III Conferência Mundial contra o Racismo, Discriminação Racial, Xenofobia

Argum., Vitória, v. 10, n. 1, p. 293-308, jan./abr. 2018. 
e Intolerâncias Correlatas, ocorrida em Durban, na África do Sul, em setembro de 2001. A conferência também influenciou outras mudanças como a utilização do critério de autodeclaração para cor/raça pelo IBGE; o Estatuto da Igualdade Racial; a adoção de um sistema de cotas raciais para o acesso ao ensino superior e mercado de trabalho; a obrigatoriedade do ensino de história e cultura africana, afro-brasileira e indígena no ensino básico. $\mathrm{O}$ referido programa constituiu um novo momento nas políticas públicas voltadas contra o racismo e outras formas de discriminação.

Jaccoud e Beghin (2002) assinalam que, para o atendimento e enfrentamento das desigualdades raciais no Brasil, as políticas públicas e sociais de caráter universal não se mostram suficientes. Devem estar associadas, simultaneamente, a políticas específicas. Para essas autoras, as iniciativas governamentais no enfrentamento da questão racial podem ser classificadas em ações repressivas, ações afirmativas e ações valorizativas.

\begin{abstract}
As ações afirmativas e as políticas repressivas são entendidas aqui como aquelas que se orientam contra comportamentos e condutas. As políticas repressivas visam combater o ato discriminatório - a discriminação direta - usando a legislação criminal existente. Note-se que as ações afirmativas procuram combater a discriminação indireta, ou seja, aquela discriminação que não se manifesta explicitamente por atos discriminatórios, mas sim por meio de formas veladas de comportamento cujo resultado provoca a exclusão de caráter racial (JACCOUD; BEGHIN, 2002, p. 55).
\end{abstract}

A Lei Caó é um exemplo de ação repressiva, pois define como crime o ato de praticar, induzir ou incitar a discriminação ou o preconceito de raça e cor. No que tange às ações afirmativas, as cotas em universidades e concursos públicos apresentam-se como exemplos.

Em relação às ações valorizativas, elas buscam combater estereótipos negativos, consolidados em preconceitos e racismo, que foram historicamente construídos. Tais ações reconhecem e valorizam a pluralidade étnica da sociedade brasileira. Possuem caráter permanente e não focalizado, ou seja, atingem toda a população, e não somente os segmentos que são discriminados racialmente (JACCOUD; BEGHIN, 2002). Como exemplo, cita-se a lei que obriga a inclusão da temática história e cultura africana, afro-brasileira e indígena no ensino básico.

\title{
2 AS AÇÕES AFIRMATIVAS NO BRASIL
}

No Brasil, o embrião da discussão acerca do que hoje convencionou-se chamar de ações afirmativas data de 1968. Na ocasião, técnicos do Ministério do Trabalho e do Tribunal Superior do Trabalho foram favoráveis à criação de uma legislação que obrigasse as empresas privadas a manter um percentual mínimo de negros $(20 \%, 15 \%$ ou $10 \%$, conforme o ramo de atividade e a demanda), a fim de coibir o problema da discriminação racial no mercado de trabalho (MOEHLECKE, 2002).

A proposta de lei de 1968 não chegou a ser elaborada, tendo em vista o período de ditadura militar. Sabe-se que, com isso, a discussão sobre minorias, exclusão, discriminação não cabia dentro de um Estado em que a utilização da força, da censura, da tortura, do aviltamento e do aniquilamento dos que pensavam de forma diferente não encontrava força, tampouco eco. 
Na década de 1980, a sociedade brasileira viveu e conviveu com o fortalecimento do processo de redemocratização e um forte movimento de massas em defesa das eleições diretas para presidente. Consequentemente, o debate sobre as desigualdades sociais e raciais voltaram à cena, e ganhou força também a discussão sobre ações afirmativas, ações compensatórias, reservas de vagas e políticas de cotas.

Nesse período, havia um intenso protagonismo dos movimentos sociais, entre eles o movimento negro, que pauta o debate sobre a desigualdade racial e as ações afirmativas, e encontra as condições sociais e políticas necessárias para adentrar na agenda do Estado. O movimento negro também procurou denunciar o mito da democracia racial, ao mesmo tempo em que pressionava e exigia uma postura mais ativa do Estado como resposta ao processo de exclusão e discriminação social vivenciado pela população negra no país.

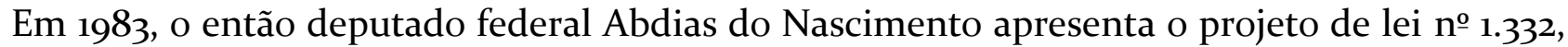
sendo o primeiro sobre a instituição de uma política de promoção de igualdade racial alinhada à adoção de medidas de caráter compensatório. Estabelecia ainda a reserva de $20 \%$ de vagas para mulheres negras e $20 \%$ para homens negros na seleção de candidatos ao serviço público; bolsas de estudos; incentivos às empresas do setor privado para a eliminação da prática da discriminação racial; incorporação da imagem positiva da família afro-brasileira ao sistema de ensino e à literatura didática, bem como introdução da história das civilizações africanas e do africano no Brasil (MOEHLECKE, 2002).

Entre 1983 e 1986, o projeto de lei tramitou nas comissões da Câmara dos Deputados e recebeu pareceres favoráveis. No entanto, aguardou até 1989 para votação no plenário daquela casa, quando foi arquivado. A não aprovação do projeto decepcionou o movimento negro, mas as reivindicações continuaram. Já em 1984, o governo considera a Serra da Barriga, em Alagoas, local do antigo Quilombo dos Palmares, como patrimônio histórico do país e cria, em 1988, a Fundação Cultural Palmares (MOEHLECKE, 2002).

A nova Constituição da República, de 1988, traz como um dos seus princípios fundamentais que todos são iguais perante a lei. Todavia, realiza algumas discriminações positivas, ou seja, reconhece o direito à diferença de tratamento legal para grupos discriminados negativamente, como as mulheres e as pessoas com deficiência. Posteriormente, alguns juristas estenderam esse entendimento à legalidade das ações afirmativas. Destarte, ainda no princípio de igualdade, as ações afirmativas fazem com que o próprio Estado reconheça as inúmeras desigualdades sociais - étnicas, raciais, de gênero -, corroborando que apenas o preceito legal não é suficiente para haver uma sociedade mais justa e igualitária.

Adentrando a década de 1990, no que tange ao movimento negro, em 1995 a Marcha Zumbi dos Palmares contra o Racismo, pela Cidadania e a Vida constituiu-se num ato de indignação e protesto contra as condições de vida da população negra brasileira. Simbolizou um momento de grande pressão junto ao poder público para pensar políticas públicas. Na ocasião, o movimento apresentou ao governo federal o Programa de Superação do Racismo e da Desigualdade Racial. Como resposta, o presidente da República, ao receber o documento em 20 de novembro 1995, institui o Grupo de Trabalho Interministerial para desenvolver políticas de valorização e promoção da população negra (MOEHLECKE, 2002). 
Em sequência, o I Programa Nacional dos Direitos Humanos (PNDH) é lançado em 1996 (BRASIL, 1996) e tem como um de seus objetivos reduzir condutas e atos de violência, intolerância e discriminação. Também visava desenvolver ações afirmativas para o acesso dos negros aos cursos profissionalizantes, às universidades e às áreas de tecnologia de ponta, além de adotar o princípio da criminalização da prática do racismo, nos Códigos Penal e de Processo Penal e formular políticas compensatórias que promovessem a comunidade negra social e economicamente.

Concebendo as ações afirmativas sob a perspectiva dos direitos humanos, Piovesan (2005) entende que determinados sujeitos de direitos e determinadas violações de direitos a que esses estão expostos exige uma resposta específica e diferenciada, pois “[...] a necessidade de conferir a determinados grupos uma proteção especial e particularizada, em face de sua própria vulnerabilidade, significa que a diferença não mais seria utilizada para a aniquilação de direitos, mas, ao revés, para a promoção de direitos" (PIOVESAN, 2005, p. 38).

Por conseguinte, as ações afirmativas são consideradas como instrumento de inclusão social e se constituem em um suporte que visa implementar a igualdade, já que estruturalmente tem-se uma sociedade desigual. Como um dos direitos constitucionais, essa é uma medida especial temporária e que visa a atender determinados grupos de indivíduos.

No entendimento do então ministro do STF Joaquim Benedito Barbosa Gomes,

As ações afirmativas se definem como políticas públicas (e privadas) voltadas à concretização do princípio constitucional da igualdade material e à neutralização dos efeitos da discriminação racial, de gênero, de idade, de origem nacional e de compleição física. Na sua compreensão, a igualdade deixa de ser simplesmente um princípio jurídico a ser respeitado por todos, e passa a ser um objetivo constitucional a ser alcançado pelo Estado e pela sociedade (GOMES, 2005, p.51).

Para Mohelecke (2002, p. 7),

[...] podemos falar em ação afirmativa como uma ação reparatória/compensatória e/ou preventiva, que busca corrigir uma situação de discriminação e desigualdade infringida a certos grupos no passado, presente ou futuro, através da valorização social, econômica, política e/ou cultural desses grupos, durante um período limitado. A ênfase em um ou mais desses aspectos dependerá do grupo visado e do contexto histórico e social (MOHELECKE, 2002, p. 7).

Por sua vez, para a Secretaria Especial de Políticas de Promoção da Igualdade Racial, ligada ao Ministério dos Direitos Humanos, as ações afirmativas são “[...] políticas públicas feitas pelo governo ou pela iniciativa privada com o objetivo de corrigir desigualdades raciais presentes na sociedade, acumuladas ao longo de anos" (BRASIL, [2017], não paginado). Para isso, busca reverter a representação negativa dos negros, promover igualdade de oportunidades e combater o preconceito e o racismo. Nesse sentido, Guimarães (2012) argumenta que a luta contra o preconceito de cor atualmente se transforma na luta pelas ações afirmativas. 


\section{A CONSTITUIÇÃO DO MARCO LEGAL DAS AÇÕES AFIRMATIVAS NO BRASIL}

Na esfera legislativa, as proposituras evidenciaram o interesse que alguns parlamentares tiveram relativamente à questão racial e às ações afirmativas. Abdias Nascimento (PDT-RJ) foi o precursor apresentando três projetos de lei na década de 1980 que se referiam à criação de uma ação compensatória, à reserva de vagas no vestibular para a etnia negra e à inscrição da discriminação como crime de lesa-humanidade. Em 1988, Carlos Alberto Caó (PDT-RJ) buscou definir o racismo como crime, sendo essa uma ação repressiva.

Na década de 1990, tem-se a apresentação da proposta de Emenda Constitucional, em 1993, do então deputado Florestan Fernandes (PT-RJ), para reservar um capítulo específico aos negros na Constituição da República. A então senadora Benedita da Silva (PT-RJ) apresentou, em 1995, os projetos de lei 13 (BRASIL, 1995c) e 14 (BRASIL, 1995b), que reservavam vagas/cotas para alunos carentes e afrodescendentes nas universidades. Já o deputado federal Paulo Paim (PT-RS), em 1995, no PL no 1.239 (BRASIL, 1995a), previa indenização para os descendentes de escravos no Brasil. Em 1998, Luiz Alberto (PT/BA) apresentou o PL no 4.567 (BRASIL, 1998a) que previa a criação de um Fundo Nacional para o Desenvolvimento de Ações Afirmativas e o PL no 4.568 (BRASIL, 1998b), solicitando a criação do Conselho Nacional de Promoção da Igualdade e Oportunidades. Em 1999, Antero Paes de Barros (PSDB/MT) apresenta o PL no 298 (BRASIL, 1999a), estabelecendo cotas para alunos egressos de escolas públicas nas universidades. Nesse mesmo ano, Nice Lobão (PFL/MA) apresenta o PL no 73 (BRASIL, 1999c) que iria dispor sobre o ingresso nas universidades. Ainda em 1999, Esther Grossi (PT/RS) e Ben-Hur Ferreira (PT/MS), apresentam o PL no 259 (BRASIL, 1999b) solicitando a alteração na Lei de Diretrizes e Bases da Educação Nacional para incluir, no currículo do ensino básico, a temática história e cultura afro-brasileira. Importa ressaltar que essa é uma ação valorizativa.

Desse modo, veem-se muitas iniciativas por parte do Poder Legislativo nas décadas de 1980 e 1990. Porém, assim como em 1968, não encontraram forças políticas e sociais suficientes, pois nenhum dos projetos de lei citados logrou aprovação. É somente a partir do compromisso assumido pelo Estado brasileiro na Conferência de Durban, em 2001, que as primeiras políticas de ações afirmativas para a população negra começaram a ser aprovadas e implementadas pelo poder público'.

Em 2002, o então presidente Fernando Henrique Cardoso cria o Programa Diversidade na Universidade com a finalidade de favorecer o acesso ao ensino superior dos afrodescendentes e indígenas brasileiros. No ano seguinte, o então presidente da República, Luiz Inácio

\footnotetext{
${ }^{1}$ Em 2001, o Ministério do Desenvolvimento Agrário (MDA) e o Instituto Nacional de Colonização e Reforma Agrária (Incra) reservavam, por meio de portaria, $45 \%$ de suas vagas para mulheres, negros e pessoas com deficiência na sua estrutura institucional. Ainda nesse ano, o Ministério da Justiça determinou a contratação, até o fim de 2002, de 20\% de negros, $20 \%$ de mulheres e $5 \%$ de pessoas com deficiência para os cargos de assessoramento. O Ministério da Cultura, em 2002, adota cotas de 20\% no preenchimento de funções de direção e assessoramento superior, além de determinar cláusulas de promoção da igualdade nos convênios ou cooperação técnica. O Ministério das Relações Exteriores, também em 2002, concedeu 20 bolsas de estudos a afrodescendentes que objetivavam a carreira diplomática. Em 2003, o Ministério da Comunicação determinou que todas as campanhas publicitárias do governo federal deveriam respeitar a diversidade racial brasileira (MOEHLECKE, 2002; MORAES, 2013).
}

Argum., Vitória, v. 10, n. 1, p. 293-308, jan./abr. 2018. 
Lula da Silva, transforma na lei no 10.639 (BRASIL, 2003) a propositura dos deputados Esther Grossi e Ben-Hur Ferreira.

Em 2005, o senador Paulo Paim (PT-RS) apresenta o PL no 6.264 (BRASIL, 2005) que instituiria o Estatuto da Igualdade Racial, o qual somente tornou-se lei em 2010.

A então presidenta Dilma Rousseff converte a proposta da deputada Nice Lobão, no ano de 2012, na lei no 12.711, a famosa Lei das Cotas do ensino superior público. A referida legislação foi alterada em 2016 pelo presidente Michel Temer, em razão do PL nº 46/2015 do senador Cassio Rodrigues da Cunha Lima (PSDB/PB), que incluía também os/as estudantes com deficiência) na reserva de vagas.

O PL no 6.738/2013, apresentado pelo Executivo, reservava aos negros cotas nos concursos públicos. Votado e aprovado pelo Congresso Nacional, tornou-se a lei no 12.990/2014.

A seguir, o Quadro 1 sistematiza a trajetória das propostas legislativas e executivas acerca das ações afirmativas (abarcando algumas ações repressivas e valorizativas), assim como destaca a conversão em leis ordinárias pelo Poder Executivo dos projetos de lei.

Quadro 1. Propostas legislativas e executivas acerca das ações afirmativas.

\begin{tabular}{|c|c|c|c|}
\hline Ano & Autor(a)/Partido/UF & $\begin{array}{l}\text { No recebido no } \\
\text { Legislativo }\end{array}$ & Conteúdo da proposta \\
\hline 1983 & $\begin{array}{l}\text { Abdias Nascimento (PDT- } \\
\text { RJ) }\end{array}$ & $\begin{array}{l}\text { PL no } 1.332 \\
\text { (BRASIL, 1983) }\end{array}$ & $\begin{array}{l}\text { Dispõe sobre Ação Compensatória, visando a } \\
\text { implementação do princípio da isonomia social } \\
\text { do negro. }\end{array}$ \\
\hline 1983 & $\begin{array}{l}\text { Abdias Nascimento (PDT- } \\
\text { RJ) }\end{array}$ & $\begin{array}{l}\text { PL no } 1.661 \\
\text { (BRASIL, 1983) }\end{array}$ & $\begin{array}{l}\text { Dispõe sobre o crime de Lesa Humanidade: } \\
\text { discriminar pessoas, individual ou coletivamen- } \\
\text { te, em razão de cor, raça ou etnia. }\end{array}$ \\
\hline 1984 & $\begin{array}{l}\text { Abdias Nascimento (PDT- } \\
\text { RJ) }\end{array}$ & $\begin{array}{l}\text { PL no } 3.196 \\
\text { (BRASIL, 1984) }\end{array}$ & $\begin{array}{l}\text { Reserva } 40 \% \text { das vagas abertas nos concursos } \\
\text { vestibulares do Instituto Rio Branco para can- } \\
\text { didatos de etnia negra. }\end{array}$ \\
\hline 1988 & $\begin{array}{l}\text { Carlos Alberto Caó (PDT- } \\
\text { RJ) }\end{array}$ & $\begin{array}{l}\text { PL no } 668 \\
\text { (BRASIL, 1988) }\end{array}$ & $\begin{array}{l}\text { Define os crimes resultantes de preconceito de } \\
\text { raça ou cor. }\end{array}$ \\
\hline 1989 & José Sarney & $\begin{array}{l}\text { Lei no } 7 \cdot 716 \\
\text { (BRASIL, 1989) }\end{array}$ & $\begin{array}{l}\text { Transformação em Lei Ordinária n. 7.716 do PL } \\
668 / 1988 \text {. Lei Caó. }\end{array}$ \\
\hline 1993 & Fernandes & PEC n. ${ }^{o} 008583-6$ & $\begin{array}{l}\text { Título VIII (Da Ordem Social), Capítulo IX (Dos } \\
\text { Negros). }\end{array}$ \\
\hline 1995 & Benedita da Silva (PT/RJ) & $\begin{array}{l}\text { PL n⿳0 } 13 \\
\text { (BRASIL, 1995a) }\end{array}$ & $\begin{array}{l}\text { Dispõe sobre a instituição de cota mínima de } \\
20 \% \text { (vinte por cento) das vagas das instituições } \\
\text { publicas de ensino superior para alunos caren- } \\
\text { tes. }\end{array}$ \\
\hline 1995 & Benedita da Silva (PT/RJ) & $\begin{array}{l}\text { PL Lei } \mathrm{n}^{\mathbf{0}} 14 \\
\text { (BRASIL, 1995b) }\end{array}$ & $\begin{array}{l}\text { Dispõe sobre a instituição de cota mínima para } \\
\text { os setores etnoraciais, socialmente discrimina- } \\
\text { dos em instituições de ensino superior. }\end{array}$ \\
\hline 1995 & Paulo Paim (PT/RS) & $\begin{array}{l}\text { PL n⿳0 } 1.239 \\
(\text { BRASIL, 1995c) }\end{array}$ & $\begin{array}{l}\text { Garante a reparação com indenização para os } \\
\text { descendentes dos escravos no Brasil. }\end{array}$ \\
\hline 1998 & Luiz Alberto (PT/BA) & $\begin{array}{l}\text { PL no } 4 \cdot 567 \\
\text { (BRASIL, 1998a) }\end{array}$ & $\begin{array}{l}\text { Cria o Fundo Nacional para o Desenvolvimento } \\
\text { de Ações Afirmativas (FNDAA). }\end{array}$ \\
\hline 1998 & Luiz Alberto (PT/BA) & $\begin{array}{l}\text { PL no } 4 \cdot 568 \\
\text { (BRASIL, 1998b) }\end{array}$ & $\begin{array}{l}\text { Cria o Conselho Nacional de Promoção da } \\
\text { Igualdade e Oportunidades (CNPIO). }\end{array}$ \\
\hline 1999 & Antero Paes de Barros & PL no 298 & Estabelece reserva de vagas nas universidades \\
\hline
\end{tabular}




\begin{tabular}{|c|c|c|c|}
\hline & $(\mathrm{PSDB} / \mathrm{MT})$ & (BRASIL, 1999a) & $\begin{array}{l}\text { públicas para alunos egressos da rede pública } \\
\text { de ensino. }\end{array}$ \\
\hline 1999 & Nice Lobão (PFL/MA) & $\begin{array}{l}\text { PL n⿳0 } 73 \\
\text { (BRASIL, 1999C) }\end{array}$ & $\begin{array}{l}\text { Dispõe sobre o ingresso nas universidades fede- } \\
\text { rais e estaduais. }\end{array}$ \\
\hline 1999 & $\begin{array}{l}\text { Esther Grossi (PT/RS) } \\
\text { Bem-Hur Ferreira (PT/MS) }\end{array}$ & $\begin{array}{l}\text { PL no } 259 \\
\text { (BRASIL, 1999b) }\end{array}$ & $\begin{array}{l}\text { Dispõe sobre a obrigatoriedade da inclusão, no } \\
\text { currículo oficial da Rede de Ensino, da temática } \\
\text { História e Cultura Afro-Brasileira. }\end{array}$ \\
\hline 2002 & Fernando Henrique Cardoso & $\begin{array}{l}\text { MPV no } 63 \\
\text { (BRASIL, 2002b) }\end{array}$ & Cria o Programa Diversidade na Universidade. \\
\hline 2002 & Ramez Tebet & $\begin{array}{l}\text { Lei no } 10.558 \\
\text { (BRASIL, 2002a) }\end{array}$ & Conversão da MPV 63 em Lei Ordinária 10.558. \\
\hline 2003 & Luiz Inácio Lula da Silva & Lei no 10.639 & $\begin{array}{l}\text { Transformação em Lei Ordinária n. } 10.639 \text { do } \\
\text { PL 259/1999. }\end{array}$ \\
\hline 2005 & Paulo Paim (PT/RS) & $\begin{array}{l}\text { PL no } 6.264 \\
\text { (BRASIL, 2005) }\end{array}$ & Institui o Estatuto da Igualdade Racial. \\
\hline 2010 & Luiz Inácio Lula da Silva & $\begin{array}{l}\text { Lei n. } 12.288 \\
\text { (BRASIL, 2010) }\end{array}$ & $\begin{array}{l}\text { Transformação em Lei Ordinária n. } 12.288 \text { do PL } \\
6.264 / 2005 \text {. }\end{array}$ \\
\hline 2012 & Dilma Rousseff & $\begin{array}{l}\text { Lei n. 12.711 } \\
\text { (BRASIL, 2012) }\end{array}$ & $\begin{array}{l}\text { Transformação em Lei Ordinária n. } 12.711 \text { do PL } \\
\text { 73/1999. }\end{array}$ \\
\hline 2013 & Dilma Rousseff & PL no 6.738 & $\begin{array}{l}\text { Reserva aos negros } 20 \% \text { das vagas oferecidas } \\
\text { nos concursos públicos. }\end{array}$ \\
\hline 2014 & Dilma Rousseff & $\begin{array}{l}\text { Lei n⿳0 } 12.990 \\
(\text { BRASIL, 2014) }\end{array}$ & $\begin{array}{l}\text { Transformação em Lei Ordinária n. } 12.990 \text { do } \\
\text { PL 6.738/2013. }\end{array}$ \\
\hline 2015 & $\begin{array}{l}\text { Cassio Rodrigues da Cunha } \\
\text { Lima (PSDB/PB) }\end{array}$ & $\mathrm{PL} \mathrm{n} \div 46$ & 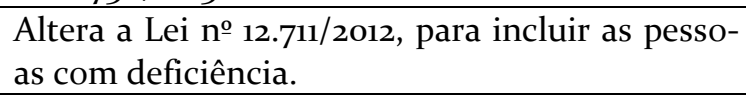 \\
\hline 2016 & Michel Temer & $\begin{array}{l}\text { Lei n⿳0 } 13.409 \\
\text { (BRASIL, 2016) }\end{array}$ & $\begin{array}{l}\text { Transformação em Lei Ordinária n. } 13.409 \text { do } \\
\text { PL 46/2015. }\end{array}$ \\
\hline
\end{tabular}

Fonte: Sistematização e elaboração dos autores (2017).

Sabe-se que a justificativa que embasou a maioria dos projetos encontrava referência na importância que a educação tem como instrumento de minimização das desigualdades sociais, assim como forma de justiça social e resgate de razões históricas como a escravidão e o massacre indígena. Logo, as instituições federais de ensino são tomadas como agentes estratégicos na construção de uma cultura dos direitos humanos, da erradicação das desigualdades sociais e étnico-raciais, com vistas a construir uma sociedade mais equitativa.

Outrossim, as ações afirmativas são, de modo geral, definidas como políticas públicas e/ou privadas que objetivam neutralizar os efeitos de discriminações sociorraciais e valorizar a diversidade étnica da sociedade brasileira. São, também, políticas de inclusão social com o intuito de garantir a criação de oportunidades a grupos de indivíduos específicos que se encontram desfavorecidos em razão da sua cor/raça e etnia, na fruição de bens, recursos, serviços e direitos sociais. Assim sendo, não se pode conceber as ações afirmativas como sinônimo de cotas. As cotas são um tipo de ação afirmativa que reserva um percentual de vagas a certos grupos sociais (negros/as, indígenas, pessoas com deficiência, estudantes de escolas públicas e/ou baixa renda,) em universidades federais e concursos públicos.

Vale destacar que as primeiras universidades públicas que implantaram cotas em seus vestibulares foram a Universidade Estadual do Rio de Janeiro (UERJ) ${ }^{2}$, a Universidade Estadual

${ }^{2}$ Em 2002 no Rio de Janeiro, uma lei estadual estabeleceu que 50\% das vagas dos cursos de graduação das universidades estaduais fossem destinadas a alunos oriundos de escolas públicas e $40 \%$ seriam destinadas a 
do Norte Fluminense (UENF) e a Universidade do Estado da Bahia (UNEB). De acordo com Moraes (2013), a Universidade de Brasília (UnB), em 2004, foi a primeira universidade federal a adotar um sistema de cotas raciais, destinando $20 \%$ das vagas do vestibular para candidatos negros.

A instituição do sistema de cotas na UnB foi objeto da Arguição de Descumprimento de Preceito Fundamental (ADPF) ajuizada pelo Democratas (DEM) no Supremo Tribunal Federal, pois o partido político as entendia como inconstitucionais. A ação foi julgada improcedente pelo STF nos dias 25 e 26 de abril de 2012 e teve como relator do caso o ministro Ricardo Lewandowski (2012). Por unanimidade, o tribunal decidiu que as políticas de cotas étnicoraciais nas universidades estavam de acordo com a Constituição, portanto são constitucionais e contribuem para corrigir o histórico de discriminação racial no país.

No Brasil, as ações afirmativas ganharam maior notoriedade a partir da sanção da lei no 12.711/2012 (BRASIL, 2012), que implantou, impositivamente, o sistema de cotas sociais e étnico-raciais nas universidades e nos institutos federais de educação, os quais historicamente foram elitizados e brancos. Com isso, garantiram o ingresso de estudantes oriundos de escolas públicas, de baixa renda e autodeclarados pretos e pardos, indígenas e com deficiência.

Para tanto, faz-se necessário estabelecer a diferença entre cota social e cota racial. As cotas sociais são destinadas para estudantes egressos de escolas públicas e que possuem baixa renda. $\mathrm{Ou}$ seja, as universidades e os institutos federais obrigam-se a reservar no mínimo $50 \%$ de suas vagas para estudantes oriundos exclusivamente de escolas públicas. Desse percentual, ou seja, 25\% dessas vagas devem ser destinadas para estudantes que, além de serem oriundos de escolas públicas, simultaneamente possuam renda per capita igual ou inferior a 1,5 salário mínimo. Os 25\% restantes são destinados aos estudantes de escolas públicas, independentemente da renda familiar.

As cotas raciais destinam-se às pessoas autodeclaradas pretas, pardas ou indígenas, de acordo com a proporcionalidade dessa população na unidade da federação onde está instalada a instituição de ensino, medida pelo último censo do IBGE. A partir da promulgação da lei no 13.409/2016 (BRASIL, 2016), incluíram-se também, nessa proporcionalidade da cota racial, os/as estudantes com deficiência.

No Brasil, as desigualdades sociais são também raciais. A pobreza, a violência, o analfabetismo, o feminicídio têm cor. Por essa razão, apenas as cotas sociais não conseguem alterar significativamente a desigualdade racial. É necessário levar em conta que a raça em nosso país “[...] constitui-se num eficiente operador social que mantém estável ou amplia as desigualdades [...]" (BERNARDINO, 2004, p.29). Portanto, ser negro/a no Brasil é ter oportunidades reduzidas. Isso posto, embora cada cota tenha a sua especificidade, ambas guardam relação, ou seja, uma cota não exclui a outra.

candidatos negros e pardos. No Paraná, também em 2002, o governo estadual regulamentou uma lei que garantia três vagas em cada uma das cinco universidades estaduais a membros de comunidades indígenas da região onde estão localizadas as instituições (MOEHLECKE, 2002). 
Estatísticas mostram que grande parte da população pobre, discriminada e excluída é negra. Sofre um duplo preconceito: pela sua condição social e pela cor de pele. E isso não é mera coincidência; é fruto do processo de formação da sociedade brasileira. Nesse sentido, concorda-se com Lewandowski (2012) em que as desigualdades entre negros e brancos não são resultados de diferenças genéticas ou biológicas, mas decorrem de séculos de dominação dos brancos sobre os negros, que posicionaram, nos âmbitos econômico, social e político, tal população como inferior. Por isso, na medida em que as distorções históricas vão sendo corrigidas, não mais serão necessárias políticas de ações afirmativas, pois seu objetivo já fora alcançado.

\section{CONSIDERAÇÕES FINAIS}

As discussões apresentadas neste artigo possibilitaram a compreensão de que as ações afirmativas são, relativamente, políticas sociais recentes no Brasil, enquanto que em outras nações se constituíram na metade do século 20. No entanto, em todos os países o protagonismo dos movimentos sociais foi decisivo para compelir o Estado a assumir uma postura mais ativa em relação à questão racial.

Nesse sentido, o movimento negro e a implantação das ações afirmativas colaboraram para sepultar o mito da democracia racial e reconhecer, definitivamente, o Brasil como um país desigual. No concernente aos negros/as em todos os âmbitos, esses/as possuem, em relação à população branca, oportunidades e possibilidades reduzidas. Em vista disso, as ações afirmativas podem contribuir para fomentar uma cultura de direitos humanos pautada na equidade, na emancipação dos sujeitos, na democratização dos direitos, na ampliação e consolidação da cidadania.

Outrossim, as ações afirmativas não podem ser entendidas apenas no sentido restrito de resgate e reparações de razões históricas. É preciso considerar que segmentos populacionais permanecem excluídos, marginalizados e continuam a sofrer todos os tipos de violação de direitos e preconceitos em razão de sua cor e etnia. O racismo existe e as cotas não o criaram, mas sim auxiliaram a colocar em debate a sua existência e permanência.

Ademais, além de discutir as cotas, a questão racial, o racismo institucional, o racismo científico, convém destacar que a categoria profissional dos/as assistentes sociais precisa compreender que raça e classe se relacionam e que tais mediações devem se fazer presentes nas intervenções, pois o seu trabalho não está imune a uma conjuntura em que o crescimento e o fortalecimento do (neo)conservadorismo se evidenciam a cada dia. Expressando-se em práticas fascistas, xenofóbicas, em manifestações cotidianas de ódio e violência, em que a intolerância, a discriminação e o preconceito contra quem pensa e/ou age diferente são constantes e crescentes.

A discriminação e o preconceito são frutos de uma construção sócio-histórica e de um tipo determinado de sociabilidade, em que a pessoa negra foi reduzida à condição de objeto, negando-lhe o princípio básico da condição humana que é a liberdade. Contudo, o serviço social, por meio de seu projeto ético-político, possui compromissos e valores éticos que objetivam eliminar todas as formas de preconceito, além de incentivar o respeito à diversidade, à participação de grupos socialmente discriminados e a opção por um projeto profissional vin-

Argum., Vitória, v. 10, n. 1, p. 293-308, jan./abr. 2018. 
culado ao processo de construção de uma nova ordem societária, sem dominação e exploração de classe, etnia e gênero.

Por fim, destaca-se a escassa produção teórica no âmbito do serviço social acerca dessa temática, o que denota a necessidade de outros estudos e de uma maior discussão sobre a questão racial dentro da categoria profissional. Por isso, as ações afirmativas, contemplando as cotas sociais, étnico-raciais, indígenas e pessoas com deficiência, devem ser tema de problematização e produção de conhecimento entre os/as assistentes sociais.

\section{REFERÊNCIAS}

BEHRING, E. R. Política social no contexto da crise capitalista. In: SERVIÇO social: direitos sociais e competências profissionais. Brasília (DF): CFESS; ABEPSS, 2009, p. 302-321.

BERNARDINO, J. Levando a raça a sério: ação afirmativa e correto reconhecimento. In: BERNARDINO, J.; GALDINO, D. (Orgs.). Levando a raça a sério: ação afirmativa e universidade. Rio de Janeiro: DP\&A, 2004. p. 15-38.

BRASIL. Ministério dos Direitos Humanos. Secretaria Especial de Políticas de Promoção da Igualdade Racial. O que são Ações Afirmativas. Brasília (DF), [2017?]. Disponível em: <http://www.seppir.gov.br/assuntos/o-que-sao-acoes-afirmativas>. Acesso em: 1o set. 2017.

BRASIL. Presidência da República. Lei no 13.409, de 28 de dezembro de 2016. Altera a Lei $n^{\circ}$ 12.711, de 29 de agosto de 2012, para dispor sobre a reserva de vagas para pessoas com deficiência nos cursos técnico de nível médio e superior das instituições federais de ensino. Brasília (DF), 2016. Disponível em:

<http://www.planalto.gov.br/ccivil_03/_ato2015-2018/2016/lei/L13409.htm>. Acesso em: 22 fev. 2018.

BRASIL. Presidência da República. Lei no 12.990, de 9 de junho de 2014. Reserva aos negros $20 \%$ (vinte por cento) das vagas oferecidas nos concursos públicos para provimento de cargos efetivos e empregos públicos no âmbito da administração pública federal, das autarquias, das fundações públicas, das empresas públicas e das sociedades de economia mista controladas pela União. Brasília (DF), 2014. Disponível em: <http://www.planalto.gov.br/ccivil_03/_at02011-2014/2014/lei/l1299o.htm>. Acesso em 20 fev. 2018.

BRASIL. Congresso. Câmara. PL no 6.738, de 7 de novembro de 2013. Reserva aos negros vinte por cento das vagas oferecidas nos concursos públicos para provimento de cargos efetivos e empregos públicos no âmbito da administração pública federal, das autarquias, das fundações públicas, das empresas públicas e das sociedades de economia mista controladas pela União. Brasília (DF), 2013. Disponível em: <http://www.camara.gov.br/sileg/integras/1177155.pdf>. Acesso em: 13 fev. 2018.

BRASIL. Presidência da República. Lei no 12.711, de 29 de agosto de 2012. Dispõe sobre o ingresso nas universidades federais e nas instituições federais de ensino técnico de nível médio e dá outras providências. Brasília (DF), 2012. Disponível em: 
<http://www.planalto.gov.br/ccivil_03/_ato2011-2014/2012/lei/l12711.htm>. Acesso em: 15 fev. 2018.

BRASIL. Presidência da República. Lei no 12.288, de 20 de julho de 2o1o. Institui o Estatuto da Igualdade Racial; altera as Leis $n^{\text {os }} 7 \cdot 716$, de 5 de janeiro de $1989,9.029$, de 13 de abril de 1995, 7.347, de 24 de julho de 1985, e 10.778, de 24 de novembro de 2003. Brasília (DF), 2010. Disponível em: <http://www.planalto.gov.br/ccivil_03/_ato20072010/2010/lei/l12288.htm>. Acesso em: 14 fev. 2018.

BRASIL. Congresso. Câmara. PL no 6.264, de 25 de novembro de 20o5. Institui o Estatuto da Igualdade Racial. Brasília (DF), 2005. Disponível em:

<http://www.camara.gov.br/proposicoesWeb/fichadetramitacao?idProposicao=307731 >. Acesso em: 13 fev. 2018.

BRASIL. Presidência da República. Lei no 10.639, de 9 de janeiro de 2003 . Altera a Lei $n^{\circ}$ 9.394, de 20 de dezembro de 1996, que estabelece as diretrizes e bases da educação nacional, para incluir no currículo oficial da Rede de Ensino a obrigatoriedade da temática "História e Cultura Afro-Brasileira", e dá outras providências. Brasília (DF), 2003. Disponível em: <http://www.planalto.gov.br/ccivil_03/leis/2003/L10.639.htm>. Acesso em: 13 fev. 2018.

BRASIL. Presidência da República. Lei no 10.558, de 13 de novembro de 2oo2. Cria o Programa Diversidade na Universidade, e dá outras providências. Brasília (DF), $2002 a$. Disponível em: <http://www.planalto.gov.br/ccivil_03/leis/2002/L10558.htm>. Acesso em: 12 fev. 2018.

BRASIL. Presidência da República. Medida Provisória no 63, de 26 de agosto de 2002. Cria o Programa Diversidade na Universidade, e dá outras providências. Brasília (DF), 2002b. Disponível em: <http://www.planalto.gov.br/ccivil_03/mpv/Antigas_2002/63.htm>. Acesso em: 13 fev. 2018.

BRASIL. Presidência da República. Decreto no 4.228, de 13 de maio de 2oo2. Institui, no âmbito da Administração Pública, o Programa Nacional de Ações Afirmativas e dá outras providências. Brasília (DF), 2002c. Disponível em:

<http://www.planalto.gov.br/ccivil_03/decreto/2002/d4228.htm>. Acesso em: 11 fev. 2018.

BRASIL. Congresso. Câmara. PL no 298, de 4 maio de 1999. Estabelece reserva de vagas nas universidades públicas para alunos egressos da rede pública de ensino. Brasília (DF), 1999a. Disponível em: <https://www25.senado.leg.br/web/atividade/materias//materia/40353/pdf>. Acesso em: 14 fev. 2018.

BRASIL. Congresso. Câmara. PL no 259, 11 de março de 1999. Dispõe sobre a obrigatoriedade da inclusão, no currículo oficial da Rede de Ensino, da tematica "História e Cultura Afro-Brasileira" e dá outras providências. Brasília (DF), 1999b. Disponível em: $<$ http://www.camara.gov.br/proposicoesWeb/fichadetramitacao?idProposicao=15223>. Acesso em: 10 fev. 2018. 
BRASIL. Congresso. Câmara. PL no 73, 24 de fevereiro de 1999. Dispõe sobre o ingresso nas universidades federais e estaduais e dá outras providências. Brasília (DF), 1999c. Disponível em:

<http://www.camara.gov.br/proposicoesWeb/fichadetramitacao?idProposicao=15013>. Acesso em: 11 fev. 2018.

BRASIL. Congresso. Câmara. PL no 4.567, de 28 de maio de 1998. Cria o Fundo Nacional para o Desenvolvimento de Ações Afirmativas (FNDAA). Brasília (DF), 1998a. Disponível em:

<http://www.camara.gov.br/proposicoesWeb/fichadetramitacao?idProposicao=25679>. Acesso em: 10 fev. 2018.

BRASIL. Congresso. Câmara. PL no 4.568, de 1998, de 28 de maio de 1998. Cria o Conselho Nacional de Promoção da Igualdade e Oportunidades - (CNPIO). Brasília (DF), 1998b. Disponível em:

<http://www.camara.gov.br/proposicoesWeb/fichadetramitacao?idProposicao=222591>. Acesso em: 14 fev. 2018.

BRASIL. Ministério da Justiça. Programa Nacional de Direitos Humanos. Brasília (DF), 1996.

BRASIL. Congresso. Câmara. PL 1.239, 21 de novembro de 1995. Garante a reparação com indenização para os descendentes dos escravos no Brasil. Brasília (DF), 1995a Disponível em:

<http://www.camara.gov.br/proposicoesWeb/fichadetramitacao?idProposicao=16454>. Acesso em: 10 fev. 2018.

BRASIL. Congresso. Senado. PL no 14, 22 de fevereiro de 1995. Dispõe sobre a instituição de cota mínima para os setores etno-raciais, socialmente discriminados em instituições de ensino superior. Brasília (DF), 1995b. Disponível em:

<http://www.lexml.gov.br/urn/urn:lex:br:senado.federal: projeto.lei;pls:1995-02-22;14>. Acesso em: 12 fev. 2018.

BRASIL. Congresso. Câmara. PL no 13, de 16 de fevereiro de 1995. Estabelece requisitos para a concessão de beneficio de incentivo fiscal nas áreas de atuação da SUDAM e da SUDENE. Brasília (DF), 1995c. Disponível em:

<http://www.camara.gov.br/proposicoesWeb/fichadetramitacao?idProposicao=170120 > Acesso em: 10 fev. 2018.

BRASIL. Presidência da República. Lei no 7·716, de 5 de janeiro de 1989. Define os crimes resultantes de preconceito de raça ou de cor. Brasília (DF), 1989. Disponível em: $<$ http://www.planalto.gov.br/ccivil_03/leis/L7716.htm>. Acesso em: 10 fev. 2018.

BRASIL. Congresso. Câmara. PL no 668, de 8 de agosto de 1988. Define os crimes resultantes de preconceito de raça ou de cor. Brasília (DF), 1988. Disponível em: $<$ http://www.camara.gov.br/proposicoesWeb/fichadetramitacao?idProposicao=180567>. Acesso em: 11 fev. 2018. 
BRASIL. Congresso. Câmara. PL no 3.196, de 13 de abril de 1984. Reserva quarenta por cento das vagas abertas nos concursos vestibulares do Instituto Rio Branco para candidatos de etnia negra. Brasília (DF), 1984. Disponível em:

<http://www.camara.gov.br/proposicoesWeb/prop_mostrarintegra;jsessionid=879CBB32F62 989492DDAABE338120CE6.proposicoesWeb2? codteor=1162303\&filename=Avulso+PL+3196/1984>. Acesso em: 12 fev. 2018.

BRASIL. Câmara dos Deputados. PL no 1.661, de 3 de agosto de 1983. Dispõe sobre o crime de lesa humanidade: discriminar pessoas, individualmente ou coletivamente, em razão de cor, raça ou etnia. Brasília (DF), 1983. Disponível em:

<http://www.camara.gov.br/proposicoesWeb/prop_mostrarintegra;jsessionid=E7Fo9 $\mathrm{C}_{3} 6 \mathrm{E}_{7} \mathrm{~B}$ E3B930723AoD6CFoo84EF.proposicoesWeb2?codteor=1164710\&filename=Avulso+PL+1661/1983>. Acesso em: 13 fev. 2018.

COUTO, B. R. O direito social e a assistência social na sociedade brasileira: uma equação possível? 4. ed. São Paulo: Cortez, 2010.

FERES JR., J.; DAFLON, V. T. Ação afirmativa na Índia e no Brasil: um estudo sobre a retórica acadêmica. Sociologias, Porto Alegre, ano 17, n. 40, p. 92-123, set./dez. 2015.

GOMES, J. B. B. A Recepção do Instituto da Ação Afirmativa pelo Direito Constitucional Brasileiro. In: SANTOS, Sales Augusto dos (Org.). Ações afirmativas e combate ao racismo nas Américas. Brasília (DF): UNESCO; BID; Ministério da Educação, 2005. p. 47-82.

GUIMARÃES, A. S. A. Preconceito racial: modos, temas e tempos. 2. ed. São Paulo: Cortez, 2012. (Preconceitos, v. 6).

JACCOUD, L. de B.; BEGHIN, N. Desigualdades raciais no Brasil: um balanço da intervenção governamental. Brasília (DF): IPEA, 2002.

LEWANDOWSKI. R. Arguição de Descumprimento de Preceito Fundamental 186 Distrito Federal: voto. Brasília (DF): Superior Tribunal Federal, 2012.

MOEHLECKE, S. Ação afirmativa: história e debates no Brasil. Cadernos de Pesquisa, São Paulo, n. 117, p. 197-217, nov. 2002.

MORAES, F. No país do racismo institucional: dez anos de ações do GT Racismo no MPPE. Coordenação Assessoria Ministerial de Comunicação Social do MPPE, Grupo de Trabalho sobre Discriminação Racial do MPPE - GT Racismo. Recife: Procuradoria Geral de Justiça, 2013.

PIOVESAN, F. Ações Afirmativas sob a Perspectiva dos Direitos Humanos. In: BRASIL. Ministério da Educação. SANTOS, A. dos S. (Org.). Ações Afirmativas e Combate ao Racismo nas Américas. Brasília (DF): Ministério da Educação; UNESCO, 2005. 
SILVA, C. B. R. da. Ações Afirmativas: uma proposta de superação do racismo e das desigualdades. Políticas Públicas, São Luís, v. 14, n. 1, p. 67-76, 2010.

SILVA, L. H. O. Ações afirmativas. Maquinações, Londrina, v. 1, p. 74-76, 2007.

Cassia Engres MOCELIN. Participou da concepção, delineamento, análise e interpretação dos dados, da redação do artigo, da sua revisão crítica e da aprovação da versão a ser publicada.

Graduada em Serviço Social. Especialista em Gestão Escolar (UCB). Especialista em Gestão de Organização Pública em Saúde (UFSM). Especialista em Gestão Pública (UFSM). Mestra em Extensão Rural (UFSM). Doutoranda no Programa de Pós-Graduação em Serviço Social da PUCRS.

Celso José MARTINAZZO. Participou da redação do artigo, da sua revisão crítica e da aprovação da versão a ser publicada.

Mestre em Educação (UFSM). Doutor em Educação (UFRGS). Pós-doutor pela Universidade do Minho (Uminho). Professor titular do Departamento de Humanidades e Educação e do Programa de Mestrado e Doutorado em Educação nas Ciências da UNIJUÍ.

Gleny Terezinha Duro GUIMARÃES. Participou da revisão crítica do artigo e da aprovação da versão a ser publicada.

Graduação em Serviço Social pela Pontifícia Universidade Católica do Rio Grande do Sul (1986). Graduação em Pedagogia pela Universidade Federal do Rio Grande do Sul (1987). Graduação em Filosofia pela Pontifícia Universidade Católica do Rio Grande do Sul (2017). Mestrado em Serviço Social pela Pontifícia Universidade Católica do Rio Grande do Sul (1991). Doutorado em Serviço Social pela Pontifícia Universidade Católica de São Paulo (1995). Possui Pós-Doutorado em Serviço Social pela Universidade Católica Portuguesa - Lisboa (2005). 